\title{
Implementing STREMII: A practical guide for crisis communication on social media during hurricanes and natural disasters
}

\author{
Margaret C. Stewart \\ University of North Florida \\ Jacksonville, FL United States \\ Cory Young \\ Ithaca College \\ Ithaca, NY United States
}

\begin{abstract}
This paper details a practical series of recommendations to implement the two ongoing stages of the STREMII model - Social Listening and Responsive Engagement - during a crisis event. First, we outline the original STREMII model, then detail and discuss a revised and updated version of the model. Then, we describe steps for getting started using the STREMII model for social media crisis communication, and, finally, present suggestions for uses of best practice for the model.
\end{abstract}

Keywords — social media, crisis communication, STREMII model, hurricanes, natural disasters

SUGGESTED CITATION: Stewart, M. C., \& Young, C. (2018). Implementing STREMII: A practical guide for crisis communication on social media during hurricanes and natural disasters. Proceedings of the International Crisis and Risk Communication Conference (pp. 27-29). Orlando, FL. USA. Nicholson School of Communication. https://doi.org/10.30658/icrcc.2018.8

\section{INTRODUCTION \& OVERVIEW OF STREMII}

These conference proceedings present practical considerations and action items for each of the stages of the STREMII model of crisis communication on social media during hurricanes and natural disasters. Originated in 2015 and derived from the events of Hurricane Sandy, STREMII (pronounced STREAM-ee) is proposed as a means to assist institutions and organizations with social media crisis communication using a six-stage cyclical process, including: (1) social listening, (2) targeting audience(s), (3) engaging \& responding, (4) monitoring and evaluating, (5) interacting, and (6) implementing changes [1]. More recently, the model is re-examined in the context of Hurricane Matthew events, given the advancements to social media since Hurricane Sandy (i.e. Facebook Live and crisis alerts) and the increase in social media pervasiveness. In this revisited model, the researchers propose that social listening and responsive engagement are interwoven throughout each of the original model's six stages in addition to remaining their own stages within the model as well [2].

While the original applications to Hurricanes Sandy and Matthew suggest that the model is not limited only to natural disasters, as we consider the evolution of STREMII we recognize the value in developing the model that may ideally serve as the model for social media crisis communication in hurricane, natural disaster situations, and similar, unpredictable circumstances. The unpredictable nature of storms and natural disasters aligns well with the ever-evolving nature of social media; there is value in understanding more about what occurs at the intersection of these two dynamic variables when it comes to crisis management and response. Lastly and most importantly, we realize that in order for the STREMII model to be widely adopted by organizations, agencies, and institutions during a time of crisis, we must present a practical set of actionable steps to crisis practioners and social media strategists. Our present research includes specific guidelines at each of the stages and provides overall considerations and recommendations for adopting the STREMII model and integrating it into existing crisis management plans and social media strategies. 


\section{GETTING STARTED WITH STREMII: SOCIAL LISTENING}

It is crucial to have an established Social Listening strategy prior to the onset of a crisis. During the pre-crises phase, it is important to utilize Social Listening to establish the market landscape, sentiment overview, identify specific community niches, and benchmark the needs of your constituents [3], [4]. There are five steps to getting started with Social Listening: determine listening objectives, identify where to listen, select listening tools, set up a listening structure, and listen continuously [5]. To begin, we recommend using platform-specific features to engage in listening activities. For example, the Advanced Search feature on Twitter allows for extensive searches of relevant handles and hashtags, and Facebook Insights allow you to establish a better understanding of audience dynamics and needs. Even third-party applications, such as Hootsuite and Simply Measured, contain features that foster Social Listening [6].

To maximize the use of platform search tools for Social Listening, it is essential to develop a critical and comprehensive list of keywords and hashtags [7]. Next, examine your existing tools and evaluate emerging tools. Periodic routine at intervals of no less than once per year is necessary in the rapidly changing social landscape. As mentioned, implementing a routine listening process, and then refining it routinely is also important [8]. In addition, it is beneficial to encourage listening across the organization. While the primary Social Listening duties can reside as the responsibility of the social media strategists and managers, there is no reason that others cannot point out what they notice happening in the online conversations, and join in to accentuate the positive brand attributes and ensure that consumers' needs are met. In terms of audience needs, you can demonstrate proof of listening through responsive engagement by making sure that the content and information that you share, especially during a crisis, is useful, valuable and necessary so that you are determined as the authority among your social community [3].

\section{CONSIDERATIONS FOR RESPONSIVE ENGAGEMENT ON SOCIAL MEDIA DURING CRISIS}

The International Committee for the Red Cross, International Federation of Red Cross and Red Crescent Societies, and Office for the Coordination of Humanitarian Affairs released a guide for using social media during humanitarian crisis events [9]. The report, when considered alongside the findings of our Social Listening research and the best practices of crisis communication, emphasizes several recommendations made for effective online response [10], [11], [12]. First, produce timely, actionable and useful content that meets your audience's needs, which reinforces the Social Listening needs of being useful and providing value. Respond in a prompt and timely manner and make the feedback loop visible. During a crisis, be as timely and transparent as possible, and manage expectations realistically. Through the process of Social Listening, you can manage and respond to rumors, hoaxes, and misinformation. You have the ability to identify new influencers within your community based on the activity and outcome of crisis conversations. Be consumercentered in your crisis engagement strategy, and be useful and valuable. If you are unable to provide your community with the information, resources, or assistance that they need during a crisis, determine who can step in and place your community in direct contact with the sources of solutions.

\section{STREMII RECOMMENDATIONS}

When attempting to implement the STREMII model into your existing crisis communication and social media strategies, there are several important considerations. First, avoid rapid replace. Use Social Listening, evaluation, and measurement to determine what is, and is not, working with your social media response engagement during the crisis. If necessary, adjust your message or strategy accordingly. Second, be sure to prepare for the process. Although most crisis events involve unpredictable elements, anticipate potential crises as best as possible. For example, conduct a risk assessment routinely to identify threats, and practice Social Listening regularly in order to rapidly identify and respond to potential threats online. Recognize the potential for changing target audiences and placement of these communities online. As social media continues to develop and diversify, your consumers may migrate, and it is your responsibility to ensure that you know the best channels for where to reach your consumers.

Prepare crisis messages readily and be ready to adjust according to the crisis. This affirms the tenets of the Situational Crisis Communication Theory (SCCT) framework [13], [14]. During a crisis, it is critical to be able to rely on your relationships; hence, engagement, relationship building, authenticity, and identifying influencers are all cornerstones of your social media strategy that are critical in crises. When introducing STREMII within your brand or organization, we recommend integrating organically. Identify the areas of STREMII that exist within your overall social media strategy, and begin to utilize the initial steps of STREMII in conjunction with your existing strategy efforts. Lastly, adapt STREMII according to the needs of your industry, organization, location, etc., and, most importantly, the specific crisis event.

\section{DISCUSSION \& CONCLUSION}

In closing, we have captured and discussed the phases of the STREMII model for social media crisis communication and supplied practical recommendations for the ongoing areas of responsive engagement and Social Listening. We also 
provide guidance for how to integrate STREMII into your existing social media and crisis communication strategies. Moving forward, there are ongoing opportunities for applied research using the STREMII model in strategic and crisis communication, and this body of work will benefit from ongoing adoption, adaptation, analysis, and assessment of the STREMII model.

\section{Author Biography}

Margaret C. Stewart (m.c.stewart@unf.edu, Ph.D., Indiana University of Pennsylvania, 2013) is an Assistant Professor of Communication Studies in the Department of Communication at University of North Florida in Jacksonville, Florida.

Cory Young (youngc@ithaca.edu, Ph.D., Bowling Green State University, 2001) is an Associate Professor of Communication Management and Design, in the Department of Strategic Communication at Ithaca College in upstate New York.

\section{REFERENCES}

[1] Stewart, M. C. \& Wilson, G. B. (2016, January). The dynamic role of social media during Hurricane \#Sandy: An introduction of the STREMII model to weather the storm of the crisis lifecycle. Computers in Human Behavior, 54, 639646. https://doi.org/10.1016/j.chb.2015.07.009

[2] Stewart, M. C. \& Young, C. (2017, March). Revisiting STREMII: An application of social media crisis communication during Hurricane Matthew. Paper presented at International Crisis \& Risk Communication Conference. Orlando, FL.

[3] Jackson, D. (2017). What is social listening \& why is it important? Retrieved from https://sproutsocial.com/insights/sociallistening/

[4] Newman, D. (2014). Social listening enables social business. Forbes. Retrieved from: https://www.forbes.com/sites/ danielnewman/2014/08/26/social-listening-enables-social-business/\#7f9568842b24

[5] Lardi, K. \& Fuchs, R. (2013). Social media strategy: A step-by-step guide to building your social business. [Google Book]. v/d|f Hochschulverlag AG ad der ETH Zürich.

[6] Mindruta, R. (2017). Top 15 free social media monitoring tools. Retrieved from https://www.brandwatch.com/blog/top-10free-social-media-monitoring-tools/

[7] Meg. (2017, May 10). Guide: What is social media listening \& why is it important? Retrieved from https://www.talkwalker.com/blog/social-media-listening-guide

[8] Templeman, M. (2017, January 26). Social-Listening: 5 ways to really engage with your social media audience. Forbes. Retrieved from https://www.forbes.com/sites/miketempleman/2017/01/26/how-to-really-engage-withyour-social-media-audience/3/\#28cc7e0649f7

[9] Lüge, T. (2017, September). How to use social media to better engage people affected by crises: A brief guide for those using social media in humanitarian organziations. Retrieved from https://www.icrc.org/en/document/social-media-toengage-with-affected-people

[10] Seeger, M. W., Sellnow, T. L., \& Ulmer, R. R. (2003). Communication and organizational crisis. Westport, CT: Praeger.

[11] Seeger, M. W. (2007, February 17). Best practices in crisis communication: An expert panel process. Journal of Applied Communication Research, 34(3), 232-244. https://doi.org/10.1080/00909880600769944

[12] Sellnow, T. M. \& Seeger, M. W. (2013). Theorizing crisis communication. Malden, MA: John Wiley \& Sons, Inc.

[13] Coombs, W. T. (2014). Ongoing crisis communication: Planning, managing, and responding. (4th ed.). Thousand Oaks, CA: Sage Publications, Inc.

[14] Coombs, W. T. (2007, Fall). Protecting organization reputations during a crisis: The development and application of situational crisis communication theory. Corporate Reputation Review, 10(3), 163-176. https://doi.org/10.1057/palgrave.crr.1550049 